\title{
SUNAT PADA ANAK PEREMPUAN (KHIFADZ) DAN PERLINDUNGAN ANAK PEREMPUAN DI INDONESIA: Studi Kasus di Kabupaten Demak
}

\author{
Jauharotul Farida, ${ }^{1}$ Misbah Zulfa Elizabeth, ${ }^{2}$ Moh Fauzi, ${ }^{3}$ \\ Rusmadi, ${ }^{4}$ Lilif Muallifatul Khorida Filasofa ${ }^{5}$ \\ Universitas Islam Negeri Walisongo Semarang \\ e-mail: 1jauharotul_farida@walisongo.ac.id, \\ 22zulfa_elizabeth@walisongo.ac.id, ${ }^{3}$ moh_fauzi@walisongo.ac.id, \\ ${ }^{4}$ rusmadi@walisongo.ac.id, ${ }^{5}$ liliffilasofa@walisongo.ac.id
}

\begin{abstract}
Abstrak
Female circumcision is one of the continuing practices in some countries of Africa, Europe, Latin America, and Asia, including Indonesia. In Arab, tradition of female circumcision has been widely known before the Islamic period. While in Indonesia, some areas practicing female circumcision include Java, Madura, Sumatra, and Kalimantan. This research used qualitative-ethnographic method. Data were collected through in-depth interviews to the traditional birth attendants who performed circumcision and to the baby's parents who sent their children for circumcision. In addition, Focus Group Discussion (FGD) involving medical personnel (doctors and midwives), traditional birth attendants, the parents, community leaders, religious leaders, academics, and government, was also conducted to explore the data. Then, the obtained data were analyzed by using descriptive analytical technique. The result shows that the practice of female circumcision in Demak Regency was done in 2 ways, namely symbolically and truly. Symbolically means that the practice of female circumcision was done by not cutting a female genital part, ie clitoris, but using substitute media, namely turmeric. On the other hand, the real meaning means that female circumcision was actually done by cutting little tip of the clitoris of a daughter. The time for practicing female circumcision in Demak regency was generally coincided with Javanese traditional ceremonies for infants / young children. The purpose for the daughters was in order to become sholihah and be able to control their lusts (not become "ngintil kakung" or hypersexual). Indeed, the motivation to practice this tradition is to preserve the ancestral tradition and to implement the religious command.
\end{abstract}


Sunat perempuan merupakan salah satu praktik yang saat ini masih dilakukan di beberapa negara di Afrika, Eropa, Amerika Latin, dan juga di Asia, termasuk Indonesia. Pada masyarakat Arab, tradisi sunat perempuan sudah dikenal luas sebelum periode Islam. Sementara Indonesia, beberapa wilayah yang mempraktikan sunat perempuan meliputi Jawa, Madura, Sumatera, dan Kalimantan. Penelitian ini menggunakan metode kualitatif-etnografis. Teknik pengumpulan data: Wawancara mendalam dengan dukun bayi yang melakukan sunat dan juga orang tua bayi yang mensunatkan anaknya. Focus Group Discussion (FGD) yang melibatkan tenaga medis (dokter dan bidan), dukun bayi yang melakukan sunat perempuan, orang tua anak yang disunat, tokoh masyarakat, tokoh agama, akademisi, dan pemerintah.Teknik analisis data dilakukan secara deskriptif-analitis Pada masyarakat di Kabupaten Demak. Praktik sunat perempuan pada Kabupaten Demak dilakukan dengan 2 cara, yakni secara simbolik dan secara sesungguhnya. Yang dimaksud secara simbolik adalah praktik sunat perempuan dilakukan tidak dengan memotong sebagain anggota kelamin perempuan, yakni klitoris, melainkan menggunakan media pengganti, yakni kunyit. Sedangkan yang dimaksud secara sesungguhnya adalah bahwa sunat perempuan benarbenar dilakukan dengan cara memotong sebagian kecil ujung klitoris anak perempuan. Waktu pelaksanaan sunat perempuan di masyarakat Kabupaten Demak pada umumnya bersamaan dengan upacaraupacara adat Jawa untuk bayi/anak kecil. Tujuan dilakukan sunat perempuan bagi masyarakat di Kabupaten Demak adalah agar anak perempuan tersebut menjadi anak shalihah dan dapat mengendalikan nafsu syahwatnya agar tidak "ngintil kakung" (hyperseks). Motivasi menjalankan tradisi sunat perempuan bagi masyarakat di Kabupaten Demak menjalankan tradisi leluhur dan menjalankan perintah agama.

Kata Kunci: sunat anak perempuan; perlindungan anak perempuan; Kabupaten Demak

\section{A. Pendahuluan}

Sunat adalah istilah yang berasal dari bahasa Arab: khitan. Kata itu secara etimologis berarti memotong. Dalam keilmuan Islam, berbagai buku fiqh klasik menjelaskan bahwa yang dimaksud dengan sunat adalah memotong kuluf (menghilangkan sebagian kulit) yang menutupi hasyafah atau ujung kepala penis. Adapun sunat pada anak perempuan dalam bahasa Arab disebut khifadh berasal dari kata khafdh artinya memotong ujung klitoris pada vagina.

Khitan tidak hanya diberlakukan terhadap anak laki-laki tetapi juga terhadap perempuan Praktek sunat pada anak perempuan banyak dilakukan oleh masyarakat di beberapa negara seluruh dunia. seperti Pakistan, Bangladesh, 
Malaysia, Indonesia, juga di negara-negara Afrika Utara, Timur Tengah, dan beberapa suku pedalaman di Amerika Serikat dan Australia. Namun, setiap negara tersebut memiliki persentase yang berbeda. Menurut Lembaga Amnesty International, diperkirakan 2 juta wanita dan anak perempuan disunat setiap tahunnya.

Berdasarkan data UNICEF, anak-anak perempuan yang mengalami FGM/C digolongkan menjadi dua kelompok. Kelompok pertama ialah yang berusia 0-14 tahun dan usia 15 hingga 49 tahun. Dalam kelompok ini, prevalensi FGM/C tertinggi berada di Gambia dengan 56 persen, Mauritania 54 persen dan Indonesia 49 persen. Sementara negara-negara dengan prevalensi tertinggi di kalangan anak perempuan berusia 15 hingga 49 tahun adalah Somalia dengan 98\%, Guinea 97\% dan Djibouti 93\%.

Berdasarkan penelitian yang dilakukan oleh Nantabah, dkk (2015), Di Indonesia sunat pada anak perempuan banyak dilakukan di Provinsi Jawa Barat (14,7\%), Provinsi Sumatera Utara (8,1\%), dan Jawa Timur (7,3\%). Angka sunat perempuan di Provinsi Jawa Barat dan Jawa Timur banyak dipengaruhi oleh Kyai dan ulama. Di Jawa sunat pada anak perempuan merupakan tradisi turun temurun yang dilestarikan walau mereka tidak memiliki cukup pengetahuan tentang perilaku tersebut kecuali didorong oleh alasan agama yang tidak utuh. ${ }^{1}$.

Pada masyarakat Muslim, kelompok pro-sunat pada anak perempuan, memang sering menggunakan argumen teologis yang bukan berasal dari alQur'an, melainkan hanya diambil dari kitab fiqih, dan didasarkan pada sejumlah hadis, yang kemudian mengakar dalam budaya masyarakat Indonesia yang mayoritas muslim.

Mempertimbangkan tingginya kasus sunat pada anak perempuan yang terjadi di berbagai belahan dunia, maka UNICEF bersama United Nations Population Fund (UNFPA) telah menargetkan untuk menghapus FGM/C pada 2030. Sebagai bagian dari negara yang telah berkomitmen untuk melindungi anak Indonesia dari berbagai bentuk kekerasan dan eksploitasi maka Indonesia mendukung upaya UNICEF dan UNFPA untuk tercapainya target SDG's.

\footnotetext{
${ }^{1}$ Zainul Khaqiqi Nantabah, Agung Dwi Laksono, Tumaji, “Determinan Orang Tua dalam Perilaku Sunat Anak Perempuan di Indonesia" Buletin Penelitian Sistem Kesehatan, Vol. 18 No. 1 Januari 2015: 77-86
} 
Kontroversi tentang sunat perempuan terjadi tak hanya di Indonesia, tetapi juga di negara-negara lain, mengingat hingga kini sekitar 140 juta anak perempuan maupun perempuan dewasa di Afrika, Timur Tengah dan Asia masih mengalami praktik tersebut. Berdasarkan data UNICEF, salah satu lembaga PBB yang peduli terhadap kondisi kesehatan dan perlindungan anak mengungkapkan, saat ini sebanyak 30 juta anak perempuan di bawah usia 15 tahun masih beresiko mengalami praktik sunat perempuan. PBB sendiri dalam Sidang Majelis Umum telah sepakat mengeluarkan resolusi pelarangan sunat perempuan. Dasar dari pelarangan tersebut adalah karena khitan perempuan dinilai membahayakan kesehatan reproduksi dan spikologi perempuan. Sebagai realisasi atas resolusi tersebut, Majelis Umum PBB meminta 193 negara anggotanya mengeluarkan kecaman dan larangan terhadap praktik khitan perempuan.

Penelitian ini menarik karena akan bersinggungan dengan persoalan interaksi nilai-nilai agama dan budaya dalam kehidupan masyarakat Indonesia yang memiliki kekuatan spiritualitas dalam keragaman tradisi budaya, dimana hal tersebut sangat terkait oleh bagaimana teks-teks agama itu diamalkan dalam kehidupan tradisi lokal di tengah situasi kehidupan peradaban global.

Berdasarkan latar belakang tersebut di atas, maka penelitian ini mengkaji permasalahan sebagai berikut: Bagaimana praktik sunat anak perempuan yang terjadi di Kabupaten Demak. Bagaimana konstruksi sosial praktek sunat perempuan yang terjadi di Kabupaten Demak. Apa yang dipahami masyarakat Kabupaten Demak tentang sunat pada anak perempuan.

\section{B. Konsepsi Sunat Perempuan}

Konsep sunat perempuan tidak bisa dilepaskan dari konsepsi sunat pada laki-laki. Sunat umumnya dikenal dengan istilah khitan. Secara etimologis (lughawi) merupakan bentuk masdar (verbal noun) dari filil madi khatana (خَنَ) yang berarti memotong.2 Dengan demikian, konsepsi sunat perempuan merupakan terjemahan dari bahasa Arab ختان الأنثى atau ختان البنات (khitan anak perempuan).

Praktik sunat antara laki-laki dan perempuan memiliki perbedaan. Jika lakilaki, maka yang dipotong adalah kulit dari bagian kemaluan (qulfah) yang

${ }^{2}$ Munawwir, A.W., Kamus al-Munawwir (Yogyakarta: Pustaka Progresif, 1984), h. 349. 
dipotong. Dalam istilah yang lazim di masyarakat disebut kulup, yakni kulit yang menutupi ujung alat kelamin laki-laki. Sementara sunat pada anak perempuan memotong kulit yang berbentuk "jengger ayam jantan" di bagian atas alat kelamin perempuan. Dalam istilah medis, "jengger ayam jantan" tersebut adalah

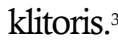

Dalam terminologi syariah Islam, sunat/khitan bagi laki-laki adalah memotong seluruh kulit yang menutup hasyafah (kepala penis) kemaluan lakilaki sehingga semua hasyafah terbuka. Sedang bagi wanita sunat / khitan adalah memotong bagian bawah kulit yang disebut nawat yang berada di bagian atas faraj (kemaluan perempuan). Sunat bagi laki-laki disebut i'dzar sedang bagi perempuan disebut $k$ hifd.

Dengan demikian, selain kata "khatn" juga terdapat istilah lain, yakni "khafadh". Perbedannya hanya pada pemakaian istilah tersebut, dimana khitan biasanya dipakai untuk laki-laki, sedangkan khafadh dipakai untuk perempuan. Dikatakan bahwa خفض البنات (khitan perempuan menurunkan kepekaan alat kelamin perempuan). Hal ini dikarenakan dengan mengkhitankan anak perempuan, berarti kepekaan alat kelaminnya tidak terlalu tinggi, sehingga libido (kekuatan seksualnya) dimasa remaja dapat terkendalikan. Meskipun terdapat perbedaan dari sisi etimologi, akan tetapi pada umumnya istilah khitan berlaku baik bagi laki-laki ataupun perempuan.

Al-Mawardhy merumuskan definisi khitan perempuan sebagai berikut:

$$
\text { ختان الأنثى قطع الجلدة التّى تكون فى اعل العضو كالنّوات اوكعرف الدّيك, والواجب }
$$

"khitan perempuan adalah memotong kulit yang paling atas pada alat kelamin yng berbentuk seperti biji-bijian, atau bagaikan jengger ayam jago. Dan yang menjadi kewajiban adalah memotoong kulit bagian atas alat tersebut dengan tidak melepaskan potongannya".

\footnotetext{
${ }^{3}$ Saad Muhammad asy-Syekh al-Marshafi, Khitan (Jakarta: Gema Insani Press , 1996), h. 13.
} 
Dari definisi khitan perempuan tersebut, dapat ditarik pemahaman bahwa syarat utama dalam khitan perempuan adalah cukup dengan memotong sedikit alat kelamin tersebut (klitoris), dan tidak perlu membuangnya.

\section{Praktik Sunat Perempuan di Indonesia}

Beragam praktik sunat perempuan memang masih banyak dilakukan di lebih dari dua puluh negara, khususnya di masyarakat muslim bermazhab Syafi'i. Di Afrika misalnya, sunat perempuan terjadi di Negara Kamerun, Sierra Leone, Ghana, Mauritania, Chad, Mesir Utara, Kenya, Tanzania, Botswana, Mali, Sudan, Somalia, Ethiopia, dan Nigeria. Sedang di Asia, praktik ini umumnya dilakukan di negara Filipina, Malaysia, Pakistan, dan Indonesia. ${ }^{4}$

Pada masyarakat di Amerika Latin, praktik sunat perempuan dijumpai di negara seperti Brasil, Meksiko bagian Timur, dan Peru. Sementara, beberapa negara Barat yang terpengaruh dengan praktik ini adalah Inggris, Perancis, Belanda, Swedia, Amerika, Australia, dan Kanada. Di negara-negara ini sunat perempuan masih dilakukan kalangan imigran yang berasal dari negara yang biasa melakukannya, meski undang-undang telah melarangnya. ${ }^{5}$

Selain itu, sunat perempuan ini juga dipraktikkan di Uni Emirat Arab, Yaman Selatan, Bahrain dan Oman. Namun hal ini tidak umum dilakukan di Saudi Arabia, Iran, Irak, Yordania, Syiria, Libanon, Maroko, Aljazair, dan Tunisia. Adapun di Turki yang bermazhab Hanafi, tidak mengenal praktik sunat perempuan ini. Begitu juga di Afghanistan dan negara Maghribi lainnya. Meski hukum di Mesir tahun 1959 telah melarang sunat perempuan, praktik ini tetap berlangsung di pedesaan. ${ }^{\circ}$

Bahkan praktik infibulasi (memotong seluruh bagian klitoris, labia minora, dan sebagian labia mayora) kabarnya juga masih terjadi. Fenomena ini juga ada di Sudan dan negara Timur Tengah tertentu. Selama ini anggapan yang berkembang, sunat perempuan hanya dilakukan perempuan muslim saja. Tetapi pada kenyataannya tidak demikian, bagi perempuan non-muslim di wilayah

${ }^{4}$ Ristiani, M., Ruli, N., dan Dian, P., Khitan Perempuan: Antara Tradisi dan Ajaran Agama, Yogyakarta: UGM dan Ford Foundation, 2003), h. 1-3.

${ }^{5}$ Ibid., h. 1-2.

${ }^{6}$ Ibid., h. 1-2; Nurtawab, E., "Lebih jauh dengan Khitan Perempuan", dalam http://www.icrp-online.org/wmprint.php? ArtID=345 
Sub-Sahara Afrika, seperti Mesir, Sudan, Somalia, Etiopia, Kenya, dan Chad, mereka juga mengalami praktik sunat perempuan ini.?

Praktik sunat perempuan di Indonesia, berbeda dengan yang terjadi di Afrika. Di Afrika sunat perempuan dilakukan secara ekstrim, seperti menyayat atau memotong seluruh bagian klitoris. Sementara pada masyarakat Indonesia, sunat perempuan biasanya dilakukan dengan cara-cara yang sederhana, seperti misalnya hanya melukai sebagaian kecil alat kelamin bagian dalam, atau sekedar simbolis saja. Simbolisasi ini biasanya dilakukan dengan meruncingkan kunyit lalu digunakan menoreh klitoris anak perempuan. Meskipun di beberapa daerah tertentu, ada pula yang menggunakan alat-alat tajam, atau bahkan dengan batu permata digosokkan ke bagian klitoris anak perempuan. ${ }^{8}$

Berdasarkan data WHO (World Health Organization) tahun 2004 ada beberapa jenis atau tipe sunat perempuan. Jenis itu antara lain, pertama, menghilangkan bagian permukaan, dengan atau tanpa diikuti pengangkatan sebagian atau seluruh klitoris. Kedua, pengangkatan klitoris diikuti dengan pengangkatan sebagian atau seluruh bagian dari labia minora. Ketiga, pengangkatan sebagian atau seluruh bagian dari organ genital luar diikuti dengan menjahit atau menyempitkan lubang vagina (infibulasi). Keempat, menusuk, melubangi klitoris dan labia, atau merenggangkan klitoris dan labia, diikuti tindakan memelarkan dengan jalan membakar klitoris atau jaringan di sekitarnya. Kelima, merusakkan jaringan di sekitar lubang vagina (angurya cuts) atau memotong vagina (gishiri cuts). Keenam, memasukkan bahan-bahan atau tumbuhan yang bersifat merusak ke dalam vagina dengan tujuan menimbulkan pendarahan, menyempitkan vagina, dan tindakan-tindakan lainnya yang dapat digolongkan dalam definisi-definisi ini. ${ }^{9}$

Dari tipe-tipe tersebut kurang lebih ada empat tipe yang dikenal dan dipraktikkan secara umum di Indonesia. Pertama, sirkumsisi. Sirkumsisi ini

${ }^{7}$ Ristiani, ibid., h. 1-2; Lily Zakiyah Munir, "Sunat dan Pelanggaran Hak", 2006, dalam http://situs.kesrepro.info/gendervaw/okt/2006/gendervaw01.htm

${ }^{8}$ Lies Marcoes Natsir, "Mempertanyakan Praktik Sunat Perempuan di Indonesia", dalam http://situs.mitrainti.org/gendervaw/feb/2003/gendervaw07.htm)

${ }^{9}$ Debu Batara Lubis, “Female Genital Mutilation: Penghilangan Hak Perempuan atas Tubuhnya", dalam Perempuan dan Hukum: Menuju Hukum yang Berperspektif Kesetaraan dan Keadilan, diterbitkan Yayasan Obor Indonesia bekerjasama dengan The Convention Watch Universitas Indonesia dan New Zealand Agency for International Development (NZAID), Jakarta, 2006. 
merupakan pengangkatan bagian permukaan dan ujung dari klitoris. Meski demikian, bentuk ini termasuk cara yang lebih halus dan tidak merusak. Kedua, excission atau clitorydectomy. Ini merupakan pengangkatan klitoris yang sering diikuti dengan pengangkatan labia minora. Ketiga, infibulasi atau pharaonic circumcission. Jenis ini merupakan pengangkatan klitoris yang diikuti dengan pengangkatan labia mayora serta menempelkan kedua sisi vagina dengan jalan menjahit atau menyatukan secara alami jaringan yang terluka dengan menggunakan media seperti duri, sutera, atau benang dari usus kucing. Pada infibulasi, ini hanya akan menyisakan lubang kecil sebesar kepala korek api untuk keluarnya cairan menstruasi. Tipe ini merupakan salah satu bentuk sunat perempuan yang ekstrim dan sangat merusak organ vital perempuan.

Pada praktik-praktik sunat perempuan yang ekstrim, biasanya dilakukan dengan menggunakan pemotong seperti pecahan kaca, besi tipis, gunting, pinset, jarum atau benda-benda tajam lainnya. sehingga, anak dan perempuan yang diinfibulasi, tidak akan memiliki besar lubang organ vital yang normal. Lubang organ vital yang kecil ini, juga tidak bisa digunakan melakukan aktivitas seksual. Hal ini dilakukan karena tujuan utama infibulasi adalah menjaga 'ke-gadis-an' perempuan yang belum menikah. Jika perempuan yang mengalami infibulasi hendak melakukan hubungan seksual, maka ia harus dibuka kembali atau defibulasi, dan nantinya juga akan dibuka lebih lebar lagi untuk kepentingan persalinan. Dalam catatan WHO, semua tipe dan jenis sunat perempuan tersebut dikategorikan dalam Female Genital Mutilation atau yang biasa disingkat FGM. ${ }^{10}$

\section{Kondisi Geografis Kabupaten Demak}

Secara geografis, Kabupaten Demak berada di Propinsi Jawa Tengah bagian Utara dan berbatasan langsung dengan Laut Jawa. Oleh karenanya, masyarakat Kabupaten Demak memiliki kebudayaan pesisiran. Kondisi lingkungan pantai di wilayah Kabupaten Demak mengalami penurunan kualitas yang cukup memprihatinkan. Panjang pantai di Kabupaten Demak yang terbentang dari barat ke timur sepanjang 34,1 kilometer mengalami kerusakan yang cukup serius akibat abrasi air laut dan mengakibatkan kerusakan serta banyak hilangnya areal pertambakan yang dimiliki petani tambak di Kabupaten Demak.

\footnotetext{
${ }^{10}$ Ibid.
} 
Secara ekonomi, Kabupaten Demak merupakan wilayah penyangga Ibu Kota Provinsi, yakni Kota Semarang yang merupakan pusat pemerintahan dan perekonomian di Jawa Tengah. Kabupaten Demak terletak pada koordinat 60 43' 26" - 70 09' 43" Lintang Selatan dan 1100 27' 58" - 1100 48' 47” Bujur Timur. Dengan bentang Barat ke Timur sepanjang $49 \mathrm{~km}$ dan bentang Utara ke Selatan sepanjang $41 \mathrm{~km}$, Kabupaten Demak memiliki batas-batas wilayah sebagai berikut: 1) Sebelah Utara: Kabupaten Jepara dan Laut Jawa 2) Sebelah Timur: Kabupaten Kudus dan Kabupaten Grobogan 3) Sebelah Selatan: Kabupaten Grobogan dan Kabupaten Semarang 4) Sebelah Barat: Kota Semarang.

Secara keseluruhan, luas wilayah Kabupaten Demak tercatat sebesar 89.743 hektar dan secara administratif terbagi menjadi 14 Kecamatan yang terdiri dari 243 desa dan 6 kelurahan. Kecamatan yang paling banyak memiliki desa/kelurahan adalah Kecamatan Bonang dan Wonosalam yang masingmasing terdiri dari 21 desa, disusul kemudian Kecamatan Guntur, Sayung, dan Wedung yang masing-masing terdiri dari 20 desa.

Sebagai wilayah pesisiran, Kabupaten Demak memiliki potensi hasil laut dan juga potensi pantai yang cukup prospektif, khususnya untuk pengembangan di bidang perikanan, budidaya hasil laut, dan pariwisata. Diperlukan memberdayakan potensi laut, peningkatan dan pembangunan sarana dan prasarana perikanan, pembangunan SDM dan pelestarian sumber daya hayati perikanan. Tambak yang terdapat di Kabupaten Demak memiliki potensi dalam peningkatan bidang perikanan khususnya perikanan darat. Tambak banyak dijumpai di Kecamatan Sayung, Karangtengah, Bonang, Demak dan Wedung.

Kondisi Demografi Masyarakat Demak Jumlah penduduk Kabupaten Demak pada tahun 2015 adalah 1.117 .901 orang terdiri atas 553.876 orang lakilaki (49,55\%), dan 564.025 orang perempuan (50,45\%). Dengan demikian, maka jelas bahwa komposisi penduduk di Kabupaten Demak lebih banyak didominasi oleh perempuan dengan sex ratio sebanyak $98.20 \%$. Rasio jenis kelamin (sex ratio) adalah banyaknya penduduk laki-laki per 100 penduduk perempuan. Dengan demikian, maka dapat dijelaskan bahwa dalam 100 orang penduduk perempuan di Kabupaten Demak terdapat 98 penduduk laki-laki.

Terdapat beberapa kecamatan dengan jumlah laki-laki lebih banyak seperti misalnya Kecamatan Guntur, Sayung, Karangtengah, dan Bonang. Sex ratio terbesar terdapat di Kecamatan Guntur yaitu 101,38 yang berarti jumlah penduduk 
laki-laki 1,38\% lebih banyak dibandingkan jumlah penduduk perempuan. Kecamatan dengan sex ratio terkecil adalah Kecamatan Demak yakni sebesar 93,72. Selengkapnya mengenai komposisi jumlah penduduk dan sex ratio penduduk di Kabupaten Demak dapat dilihat pada Tabel 1.

Tabel 1.

Jumlah Penduduk Berdasarkan Jenis Kelamin dan Sex Ratio

\begin{tabular}{|r|l|r|r|r|r|}
\hline No. & Kecamatan & \multicolumn{1}{|c|}{ Lk } & \multicolumn{1}{c|}{ Pr } & Jumlah Total & \multicolumn{1}{|c|}{ Sex Ratio } \\
\hline 1 & Mranggen & 89.296 & 90.856 & 180.152 & 98,28 \\
\hline 2 & Karangawen & 43.663 & 44.469 & 88.132 & 98.19 \\
\hline 3 & Guntur & 38342 & 37.821 & 76.163 & 101.38 \\
\hline 4 & Sayung & 52.097 & 51.835 & 103.932 & 100.51 \\
\hline 5 & Karangtengah & 31.061 & 31.049 & 62.110 & 100.04 \\
\hline 6 & Bonang & 50.605 & 50.122 & 100.727 & 100.96 \\
\hline 7 & Demak & 48.780 & 52.051 & 100.831 & 93.72 \\
\hline 8 & Wonosalam & 37.266 & 37.974 & 75.240 & 98.14 \\
\hline 9 & Dempet & 26.337 & 26.672 & 53.009 & 98.74 \\
\hline 10 & Kebonagung & 19.719 & 20.048 & 39.767 & 98.36 \\
\hline 11 & Gajah & 21.341 & 22.317 & 43.658 & 95.63 \\
\hline 12 & Karanganyar & 34.603 & 35.606 & 70.209 & 97.18 \\
\hline 13 & Mijen & 24.814 & 26.293 & 51.107 & 94.37 \\
\hline 14 & Wedung & 35.952 & 36.912 & 72.864 & 97.40 \\
\hline & Jumlah & $\mathbf{5 5 3 . 8 7 6}$ & $\mathbf{5 6 4 . 0 2 5}$ & $\mathbf{1 . 1 1 7 . 9 0 1}$ & $\mathbf{9 8 . 2 0}$ \\
\hline
\end{tabular}

Sumber: Kabupaten Dalam Angka 2016

Jika dilihat dari kepadatan penduduknya, maka pada tahun $2015 \mathrm{Ka}-$ bupaten Demak memiliki kepadatan penduduk sebanyak 1.246 orang $/ \mathrm{km} 2$. Dengan angka kepadatan mencapai lebih dari 1.000 orang/km2, maka kepadatan penduduk di Kabupaten Demak dikategorikan memiliki kepadatan penduduk cukup tinggi. Secara berurutan, penduduk terbanyak terdapat di Kecamatan Mranggen (2.494 orang/ $\mathrm{km} 2$ ), sedangkan wilayah dengan tingkat kepadatan paling rendah adalah di Kecamatan Mijen dengan kepadatan hanya mencapai 517 orang $/ \mathrm{km} 2$. Adapun selengkapnya sebagaimana terlihat pada Tabel 2.

Jika dilihat dari pemeluk Agama, maka jumlah penduduk di Kabupaten Demak pada umumnya didominasi oleh pemeluk Agama Islam dengan jumlah sebesar 1.109.489 orang, disusul kemudian Kristen sebanyak 4.799 orang, 
Katolik sebanyak 3.297 orang, dan Hindu/Budha sebanyak 316 orang. Selengkapnya mengenai jumlah penduduk berdasarkan agama yang dipeluk sebagaimana terlihat pada Tabel 3 .

Tabel 2.

Kepadatan Penduduk Berdasarkan Masing-masing Wilayah

\begin{tabular}{|r|l|r|r|r|}
\hline No. & Kecamatan & $\begin{array}{c}\text { Luas Wilayah } \\
\mathbf{( k m 2 )}\end{array}$ & $\begin{array}{c}\text { Jumlah } \\
\text { Penduduk }\end{array}$ & \multicolumn{1}{|c|}{ Kepadatan } \\
\hline 1 & Mranggen & 72.22 & 180.152 & 2.494 \\
\hline 2 & Karangawen & 66.95 & 88.132 & 1.316 \\
\hline 3 & Guntur & 57.53 & 76.163 & 1.324 \\
\hline 4 & Sayung & 78.69 & 103.932 & 1.321 \\
\hline 5 & Karangtengah & 51.55 & 62.110 & 1.205 \\
\hline 6 & Bonang & 83.24 & 100.727 & 1210 \\
\hline 7 & Demak & 61.13 & 100.831 & 1.649 \\
\hline 8 & Wonosalam & 57.88 & 75.240 & 1.300 \\
\hline 9 & Dempet & 61.61 & 53.009 & 860 \\
\hline 10 & Kebonagung & 47.83 & 39.767 & 831 \\
\hline 11 & Gajah & 67.76 & 43.658 & 644 \\
\hline 12 & Karanganyar & 50.29 & 70.209 & 1.396 \\
\hline 13 & Mijen & 98.76 & 51.107 & 517 \\
\hline 14 & Wedung & 41.99 & 72.864 & 1.735 \\
\hline & Jumlah & $\mathbf{8 9 7 . 4 3}$ & $\mathbf{1 . 1 1 7 . 9 0 1}$ & $\mathbf{1 . 2 4 6}$ \\
\hline
\end{tabular}

Sumber: Kabupaten Dalam Angka 2016

Tabel 3.

Jumlah Penduduk Berdasarkan Pemeluk Agama

\begin{tabular}{|r|l|r|r|r|r|r|}
\hline \multirow{2}{*}{ No. } & \multirow{2}{*}{ Kecamatan } & \multicolumn{3}{|c|}{ Penduduk Berdasarkan Agama } & \multirow{2}{*}{$\begin{array}{c}\text { Jumlah } \\
\text { Total }\end{array}$} \\
\cline { 3 - 6 } & & Islam & Katolik & Kristen & $\begin{array}{c}\text { Hindu/ } \\
\text { Budha }\end{array}$ & \\
\hline 1 & Mranggen & 176.616 & 1.474 & 1.896 & 166 & 180.152 \\
\hline 2 & Karangawen & 87.123 & 965 & 19 & 25 & 88.132 \\
\hline 3 & Guntur & 75.836 & 0 & 327 & 0 & 76.163 \\
\hline 4 & Sayung & 102.817 & 479 & 620 & 16 & 103.932 \\
\hline 5 & Karangtengah & 62.032 & 15 & 63 & 0 & 62.110 \\
\hline 6 & Bonang & 100.716 & 0 & 10 & 1 & 100.727 \\
\hline 7 & Demak & 99.110 & 199 & 1.458 & 64 & 100.831 \\
\hline 8 & Wonosalam & 75.180 & 31 & 29 & 0 & 75.240 \\
\hline 9 & Dempet & 52.870 & 107 & 20 & 12 & 53.009 \\
\hline
\end{tabular}




\begin{tabular}{|l|l|r|r|r|r|r|}
\hline 10 & Kebonagung & 39.592 & 5 & 170 & 0 & 39.767 \\
\hline 11 & Gajah & 43.569 & 0 & 57 & 32 & 43.658 \\
\hline 12 & Karanganyar & 70.155 & 0 & 54 & 0 & 70.209 \\
\hline 13 & Mijen & 51.014 & 22 & 71 & 0 & 51.107 \\
\hline 14 & Wedung & 72.859 & 0 & 5 & 0 & 72.864 \\
\hline & Jumlah & 1.109 .489 & 3.297 & 4.799 & 316 & 1.117 .901 \\
\hline
\end{tabular}

Sumber: Kabupaten Dalam Angka 2016

Dari tabel tersebut di atas dapat disimpulkan bahwa kondisi sosial keagamaan masyarakat Kabupaten Demak sangat diwarnai oleh Agama Islam. Apalagi Kabupaten Demak dikenal dengan sebutan Kota Wali yang menandakan corak sosial budaya keagamaan Islam sangat kental dalam keidupan masyarakat di Kabupaten Demak.

\section{Sunat Anak Perempuan di Kabupaten Demak}

Sunat anak perempuan di Kabupaten Demak masih banyak dilakukan oleh masyarakat yang dilakukan secara turun temurun, sebagaimana dinyatakan oleh seorang dukun bayi berinisial J berikut ini:

Nggih tasih kathah teng Ndemak nggen kulo... nggeh kathah.... kulo ngantos sak niki nggih tesih asring diken nyunat' (Memang di Demak daerah saya masih banyak praktek sunak anak perempuan. Sampai saat ini saya juga masih sering dipanggil untuk melakukan sunat anak perempuan) (Pernyataan Ibu berinisial J, seorang Dukun Bayi di Kabupaten Demak dalam Focus Group Discussion)

Pernyataan dukun bayi tersebut ditegaskan oleh peserta focus group discussion (FGD) yang lain, termasuk paramedis seperti dokter puskesmas dan bidan. Berdasarkan penuturan dari Ibu berinisial A, seorang bidan puskesmas di Kabupaten Demak menyatakan bahwa praktik sunat perempuan masi dilakukan oleh masyarakat di Kabupaten Demak sebagaimana pernyataan berikut ini:

Di Kabupaten Demak ini, sunat atau khitan perempuan memang masih dilakukan oleh banyak masyarakat. Praktik ini dilakukan oleh dukun bayi, dan sudah turun temurun sejak orang tua dulu (Pernyataan Ibu berinisial A, seorang bidan puskesmas di Kabupaten Demak)

Berdasarkan hasil FGD, ditemukan bahwa pada praktiknya, sunat perempuan di Kabupaten Demak, dilakukan melalui dua model, yakni dengan 
cara sesungguhnya dan ada yang dilakukan secara simbolik. Model-model tersebut bergantung pada kehendak orang tua si anak yang disunat dan juga bergantung pada dukun bayi yang bersangkutan. Terdapat dukun bayi di Kabupaten Demak yang melakukan sunat secara sesungguhnya, tetapi juga terdapat dukun bayi yang melakukan sunat secara simbolik.

Berdasarkan wawancara dengan Dukun Bayi di Kabupaten Demak berinisial IR mengatakan bahwa ia melakukan sunat perempuan dengan cara sunat yang sesungguhnya, yakni memotong sebagian pada klitoris perempuan. Menurutnya, jika hanya melakukan sunat secara simbolik (tidak memotong), khawatir dianggap bohong. Berikut penuturan dukun bayi di Kabupaten Demak:

"Saya kalau mensunat ya beneran saya gores sedikit di bagian njerone wong wedok sing koyo jengger ayam, ngantos medal getihe, wong memang carane ngoten. Ngendikane kyai nggih ngoten, ngendikane mamah dedeh teng tivi nggih ngoten. Kulo menawi mboten kados niku malah kewatir dianggap bohong, takut dosa, wong namanya sunat ya dipotong, kok malah yang dipotong kunir. Saya takut bohong, makanya kalau sunat ya saya bener-bener tak sunat, bukan simbolik" (Saya kalau mengsunat ya benar-benar saya goreskan sedikit di bagian dalam alat kelamin perempuan yang bentuknya seperti jengger ayam (klitoris), sampai keluar darahnya, karena memang caranya seperti itu (Wawancara dengan Ibu berinisial IR, Dukun Bayi yang melaksanakan sunat perempuan yang di Kabupaten Demak)

Alat ingkang kulo persiapke niku nggih pemes, alkohol, kunir. Kulo menawi nyunati dikerik sekedik ngantos medal getihe teng bagian atas vagina ingkang mrentil, diparingi kunir ten vagina diresii terus kunire kulo ketok, maos syahadat, istighfar, basmalah, terus kulo dungoaken mugi dados anak ingkang sholekhah" (alat yang saya persiapkan untuk sunat itu pisau, alkohol, dan kunyit. Pada saat saya mengsunat itu digoreskan sedikit di vagina bagian atas yang menonjol (klitoris) hingga berdarah, kemudian diberi kunir di bagian vagina, dan kemudian dibersihkan, lalu kunyitnya dipotong, saya membaca syahadat, istighfar, basmalah, dan saya do'akan semoga menjadi anak sholihah" (wawancara dengan Ibu berinisial IR, Dukun Bayi yang melaksanakan sunat perempuan yang di Kabupaten Demak)

Menawi tiyang sepuhe nyuwun dipotong nggih kulo potong sesuai penyuwunanne tiyang sepahe, guntinge nggih saking tiyang sepuhe, nggih kulo bersihi ngagem alkohol kajenge seteril" (Kalau orang tuanya meminta dipotong (bagian klitorisnya) ya saya potong sesuai dengan permintaan 
orang tuanya. Guntingnya dari orang tuanya, kemudian saya bersikan menggunakan alkohol agar steril) (wawancara dengan Ibu berinisial IR, Dukun Bayi yang melaksanakan sunat perempuan yang di Kabupaten Demak)

"Model nyunati niku nggeh sangking pak yai riyen. Sanjange nyunati niku dipotong walau cuman sebesar gula pasir saja, berdarah sedikit di bagian atas vagina, kalau anak putri tidak disunat khawatir ngintil kakung (tata cara mengsunat perempuan itu dari pak kyai dulu, katanya mengsunat perempuan itu ya dipotong sedikit di bagian dalam vagina bagian atasnya (klitorisnya) walau hanya sedikit sebesar gula pasir, berdarah. Kalau anak perempuan tidak disunat kawatir nantinya jadi "ngintil kakung" atau memiliki libido seksual yang tinggi (hiperseks)" (wawancara dengan Ibu berinisial IR, Dukun Bayi yang melaksanakan sunat perempuan yang di Kabupaten Demak).

Selain terdapat praktik sunat secara sesungguhnya, pada masyarakat di Kabupaten Demak juga terdapat praktik sunat perempuan yang dilakukan secara simbolik, yakni dilakukan dengan menggunakan media pengganti berupa kunyit yang ditempelkan di klitoris perempuan. Berbeda dengan sunat yang dilakukan secara sesungguhnya, sunat secara simbolik ini yang dipotong adalah kunyit tersebut, bukan bagian dari klitoris perempuan.

Sebelum dilakukan prosesi sunat tersebut, bagian dalam vagina bayi perempuan dibersihkan terlebih dulu menggunakan kain kasa dan alkohol. Pembersihan bagian dalam vagina tersebut dimaksudkan agar bersih dari sisasisa bedak yang biasanya banyak menempel di vagina bayi. Hal ini disebabkan umumnya orang tua selalu memberi bedak kepada bayi setelah mandi.

Pada saat pelaksanaan sunat terlebih dahulu disiapkan peralatan yang akan digunakan untuk prosesi sunatan yaitu disiapkan mangkuk berisi air setanam, kunyit, alkohol, kain kassa, silet atau pisau kecil, kemudian dukun bayi mengambil kunyit dan pisau kecil untuk di letakkan di memeknya lalu kunyit itu dipotong dan potongan kunyit itu dioleskan di memeknya. Dalam prosesi sunat tersebut, dukun bayi biasannya membaca doa-doa tertentu sebelum memulai sunat seperti basmalah, syahadat, shalawat, dan berdo'a agar kelak menjadi anak sholekhah.

Berikut ini adalah penurutan Ibu berinisial J, Dukun Bayi di Kabupaten Demak yang melakukan sunat perempuan secara simbolik: 
"Kulo menawi nyunati utowo tetesan niku modele kotor-kotoran ingkang wonten vagina bocah niku kulo rese'i bagian lempitan ngagem kain kasa, ben resik kabeh, soale kadang niku akeh kotoran saking bedak bayi. Nek kulo niku mboten dipotong jengger ayame, tapi ngagem kunir, lah kunire ingkang dipotong. Kulo mboten ngagem alat-alat untuk nyunati. Pas nyunati niku nggih kulo maos bismilah, syahadat, karo ndonga mmugi-mugi dados lare ingkah sholehah. Biasane nek menawi sampun wayahe disunat, mpun selapanan niku kulo tawari teng tiyang sepahe, niki mpun wayahe disunat dan dipotong rambutnya" (Saya kalau mengsunat atau melakukan tetesan modelnya membersihkan kotoran-kotoran yang terdapat di dalam vagina bayi perempuan, saya bersihkan bagian dalam vagina yang terlipat agar bersih semua, karena biasanya banyak kotoran yang bersumber dari bedak bayi. Kalau saya itu tidak memotong bagian dalam vagina yang seperti jengger ayam (klitoris)nya, tetapi saya menggunakan kunyit, dan kunyit tersebut yang dipotong. Saya tidak menggunakan alat-alat layaknya orang sunat. Pada saat mengsunat itu saya juga membaca basmalah, syahadat, dan berdoa agar kelak menjadi anak yang sholehah. Biasanya kalau sudah waktunya sunat pas selapanan (usia bayi 35 hari kalender Jawa) saya tawarkan ke orang tuanya, ini sudah waktunya disunat dan dipotong rambutnya (wawancara dengan Ibu berinisial J, Dukun Bayi yang melaksanakan sunat perempuan yang di Kabupaten Demak).

Hal yang sama juga diungkapkan oleh Ibu dengan inisial A, seorang dukun Bayi di Kabupaten Demak. Ia mengatakan bahwa sunat perempuan yang dia lakukan tidak dengan memotong klitoris perempuan, melainkan yang dipotong adalah kunyit yang ditempelkan ke dalam vagina anak perempuan yang disunat. Sebagaimana penuturannya berikut ini:

"Kulo niku nggih menawi nyunati bocah kuwi ga dipotong tenan Pak, mengko yo iso dadi gawe. Soale riyin niku nate wonten ingkang sunat dipotong tenan nganti dados patine, lah metu getihe niku, akhire ngantos tekan patine. Akhire nggih tiyang sepahe mboten trimo kalih dukune mau. Niku riyin jaman kulo dereng dados dukun bayi. Mangkane kulo niku pas tesih anyaran dadi dukun kulo nggih tanglet kali dukun bayi ingkang sampun pengalaman, sajane piye to nyunati bocah wedok kuwi. Jawabane dukun kuwi mau yo ora dipotong, naming nganggo kunyit, lah kunyite kuwi mau dijeputno nang nggone jenggere bocah wedok kuwi, bar niku dipotong. Tapi sanes jenggere, namung kunyite. Lah kulo tanglet kalih si mbah niku wau, lah nopo mboten dipotong nikune mbah? Lah piyambake niku njawabe ngeten, lah polomu kuwi, yo ga dipotong lah, opo kowe pingin mateni wong, ngoten 
Pak. Dadones kulo nek nyunati bocah wedok niku nggih mboten dipotong tenanan. Tapi bocah wedok kudu disunat, wong niku yo wis dadi lelakoni tiyang sepah mbiyen (saya itu kalau melakukan sunat terhadap anak perempuan tidak benar-benar dipotong Pak, nanti malah bisa jadi masalah. Soalnya dulu pernah terjadi sunat perempuan dilakukan dengan memotong sampai akhirnya bayi itu meninggal, karena mengeluarkan darah. Akibatnya, orang tuanya kemudian tidak terima atas perlakuan dukun tersebut. Kejadian itu terjadi pada saat saya masih muda, belum jadi dukun bayi, masih belum berpengalaman. Oleh karenanya, pada saat saya mulai praktik menjadi dukun bayi, saya bertanya dulu kepada dukun bayi yang sudah tua dan berpengalaman, sebenarnya bagaimana teknik melakukan sunat perempuan. Jawaban dari dukun bayi tersebut adalah tidak memotong, akan tetapi hanya menggunakan kunyit, dan kunyintnya tersebut yang dipotong, bukan jengger ayamnya (klitorisnya), melainkan hanya kunyitnya. Lah saya bertanya, apakah tidak dipotong klitorisnya mbah? Lah dukun tersebut menjawab: pikiran$\mathrm{mu}$ itu, ya tidak dipotong lah, apakah kamu pingin membunuh orang? Begitu Pak. Oleh karenanya, kalau saya menyunati anak perempuan itu tidak dipotong. Meskipun demikian, anak perempuan wajib disunat, soalnya itu sudah menjadi perintahnya orang-orang tua kita dulu) (wawancara dengan Ibu dengan inisial A, dukun bayi di Kabupaten Demak).

Dari uraian tersebut di atas, maka dapat disimpulkan bahwa praktik sunat perempuan di Kabupaten Demak dilakukan secara beragam, ada yang dilakukan secara sesungguhnya, yakni secara langsung memotong bagian pucuk klitoris meskipun hanya sedikit (sebesar gula pasir), dan ada juga yang dilakukan secara simbolik menggunakan media kunyit yang diletakan di klitoris perempuan, klitoris tersebut kemudian yang dipotong. Pada praktiknya, antara yang sesungguhnya dan yang simbolik bergantung dukun bayi yang melakukannya.

\section{Tradisi Sunat Perempuan dalam Konteks Perlindungan Anak di Indonesia}

\section{a. Sunat Perempuan sebagai Tradisi yang Bias Gender}

Apa yang telah diuraikan sebelumnya tentang gambaran mengenai tradisi sunat perempuan di Kabupaten Demak dan Kabupaten Klaten Provinsi Jawa Tengah menunjukkan bahwa praktik sunat perempuan masih eksis di tengah masyarakat, meskipun pada praktiknya telah terjadi perbedaan tata cara melaku- 
kan sunat, dimana hanya dilakukan dengan sedikit menggoreskan pisau pada bagian dalam alat kelanin perempuan, yakni klitoris. Bahkan beberapa orang hanya melakukannya secara simbolik, yakni menempelkan kunyit di dalam alat kelamin perempuan, dan kunyit tersebutlah yang dipotong menggunakan pisau. Oleh karenanya, dapat dikatakan bahwa praktik sunat perempuan di kedua wilaya tersebut tidak se-ekstrem di Afrikayang dilakukan dengan menyayat atau memotong klitoris perempuan.

Meskipun praktik sunat perempuan di kedua wilayah tersebut berbeda dengan praktik sunat perempuan di Afrika yang dikenal sangat ekstrem, yakni dengan menyayat atau memotong seluruh bagian klitoris. Akan tetapi, jika dilihat dari perspektif gender, maka tradisi sunat perempuan adalah bagian dari tradisi yang bias gender.

Pada konteks ini, tradisi sunat perempuan tidak terlepas dari makna kultural yang mempengaruhinya. Tradisi sunat perempuan sesungguhnya tidak bisa dilepaskan dari stigma tentang perempuan dalam budaya patriarki. Meskipun dalam tradisi matriarki seperti di Sumatera Barat, sunat perempuan tetap menjadi sebuah keharusan. Akan tetapi umumnya dijumpai bahwa praktik sunat perempuan memiliki tujuan agar mengurangi syahwat perempuan.

Pada konteks ini, maka sunat perempuan dimaksudkan sebagai kontrol terhadap seksualitas perempuan. Anggapan bahwa perempuan adalah penggoda karena memiliki "syahwat" besar telah menkonstruksikan mitos yang buruk dalam kehidupan perempuan. Stigma tersebut tentu saja menjerumuskan nasib perempuan, karena sesungguhnya tubuh mereka telah dikontrol oleh dunia laki-laki.

Dari perspektif feminisme, sunat perempuan menjadi bukti kuat bahwa perempuan tidak otonom atas tubuhnya sendiri. Tubuh perempuan menjadi medan pertempuran berbagai kepentingan sosial, tradisi, budaya, modal, dan agama. Perempuan tak memiliki hak dan otoritas untuk menentukan kekuasaannya atas tubuhnya sendiri. Kehidupan seksualitas perempuan diatur dan dirumuskan oleh banyak kepentingan di luar kepentingan perempuan itu sendiri. Keluarga, masyarakat, dan negara demikian dominan untuk mendefiniskan "apa tubuh perempuan itu". Masyarakat tradisional dan modern masih meyakini bahwa perempuan (dan tubuhnya) adalah realitas yang "kotor" dan "berdosa"

Pada konteks ini, maka tradisi sunat perempuan yang terjadi di tengah masyarakat, baik di Kabupaten Demak maupun di Kabupaten Klaten, 
sebenarnya menunjukkan adanya budaya yang bias gender. Hal ini misalnya bisa dilihat dari diskursus terkait tujuan sunat perempuan, yakni agar anak perempuan menjadi anak yang sholihah dan agar tidak nginthil kakung, yakni bisa mengurangi nafsu syahwatnya seorang perempuan terhadap laki-laki. Dari kedua tujuan ini saja sunat perempuan sangat bias gender, dengan alas an sebagai berikut:

Pertama, tujuan sunat perempuan adalah agar menjadi anak yang sholihah sebenarnya mengesankan bahwa anak perempuan adalah nakal, tidak baik, dan oleh karena itu perlu dilakukan treatment agar anak perempuan menjadi anak yang baik (baca: sholihah). Sementara anak laki-laki adalah anak yang baik, tidak nakal, sehingga tidak perlu dilakukan treatmen-treatmen tambahan. Kalaupun seorang anak laki-laki dilakukan sunat, maka tujuannya bukan agar menjadi anak yang sholeh, karena sesungguhnya anak laki-laki sudah baik, melainkan karena perintah agama, dan seorang laki-laki akan mendapatkan pahala jika melakukan sunat, karena ukumnya adalah sunah. Beberapa ulama bahkan menghukumi wajib. Oleh karenanya, dapat dikatakan bahwa sunat perempuan merupakan bentuk kontrol laki-laki atas perempuan.

Kedua, tujuan sunat perempuan adalah agar tidak ngintil kakung, sebenarnya mengesankan bahwa anak perempuan dianggap memiliki sifat dasar yang buruk yang merupakan bawaan sejak lahir, yaitu syahwat seksualnya yang tinggi. Oleh karenanya, perlu dilakukan treatment agar perempuan mampu mengendalikan sifat buruk tersebut. Praktik sunat perempuan yang dilakukan dengan cara memotong, menggores, ataupun dilakukan secara simbolik terhadap alat kelamin perempuan menunjukkan bahwa perempuan tidak memiliki kemerdekaan atas tubuhnya sendiri. Pada saat yang sama, memberi kesan bahwa anak laki-laki adalah anak yang nafsunya terkendali. Dengan tujuan mengendalikan awa nafsu seksualnya, juga memberi kesan bahwa seorang perempuan tidak diperbolekan melebihi laki-laki. Pada konteks ini, maka bias gender dalam tradisi sunat perempuan sangat kental.

Ketiga, tradisi sunat perempuan merupakan bentuk pelabelan (stereotip) terhadap perempuan, yakni bahwa perempuan adalah makhluk nomor dua yang tak pantas untuk mengekspresikan kebutuhan seksualnya. Hal ini menjadikan sunat perempuan sebagai salah satu cara untuk meredam dan mengebiri kebutuhannya itu. Menurut mitos-mitos yang dipercayai oleh masyarakat, perempuan tidak berhak menikmati kepuasan seksualnya. Kepuasan seksual 
perempuan hanyalah sebagai pelengkap kepuasan seksual lakilaki. Ini berarti bahwa perempuan tidak perlu dirangsang atau tidak perlu bergairah, apalagi menikmati orgasme. Untuk itulah, praktek sunat dengan cara memotong atau menggores klitoris sebagai organ seks perempuan paling sensitif dari rangsangan menjadi dibenarkan secara kultural.

Keempat, sunat perempuan justru banyak memberi mahdlarat (keburukan) bagi perempuan, karena alat kelamin perempuan diperlakukan sedemikian rupa agar nafsu seksualnya berkurang. Sementara sunat pada anak laki-laki justru mendatangkan kebaikan, seperti kebersihan dan kenikmatan seksual. Secara medis sunat bagi laki-laki dengan pemotongan kulit kepala penis adalah sangat positif. Hal ini bertujuan untuk menghindari pengumpulan kotoran dalam kelamin. Sunat pada laki-laki juga dimaksudkan untuk memberikan kenikmatan yang sempurna bagi laki-laki ketika berhubungan badan dengan pasangannya. Kepala penis yang berkulup (tidak disunat) lebih sensitif daripada yang tidak berkulup (disunat). Dengan dibuangnya kulup tersebut akan memperlama berlangsungnya hubungan seksual (terhindar dari ejakulasi prematur) sehingga secara optimal laki-laki bisa menikmati pemenuhan kebutuhan biologisnya. Hal ini tidak ditemukan dalam praktk sunat perempuan. yang terjadi justru sebaliknya, perempuan akan berkurang kenikmatan seksualnya karena tujuan sunat adala mengurangi nafsu seksualnya. ${ }^{11}$

Dengan melihat tradisi sunat perempuan dari perspektif gender seperti tersebut di atas, maka tradisi sunat perempuan sebenarnya adala praktik yang diskriminatif. Menurut Komnas Perlindungan Perempuan Indonesia, sunat perempuan adalah salah satu tradisi yang memiliki unsur kekerasan terhadap perempuan, dan oleh karenanya bertentangan dengan perlindungan perempuan.

Pada saat yang sama, dari perspektif keadilan gender, tradisi sunat perempuan juga tidak responsif gender dan tidak adil, karena dilakukan terhadap bayi-bayi perempuan yang belum bisa mengeluarkan pendapatnya sendiri tentang bagaimana mereka ingin tubuhnya diperlakukan. Sehingga yang ada kemudian, anak-anak 'dipaksa' menerima perlakuan praktik khitan itu atas nama agama dan budaya/tradisi.

${ }^{11}$ Waliko, "Telaah Atas Konsep Khitan Bagi Wanita", Jurnal Yinyang, Vol. 4 No.2 JuliDesember 2009 h. 222-233. 


\section{b. Sunat Perempuan Bertentangan dengan Prinsip-Prinsip Perlindungan Anak}

Selain bias gender, tradisi sunat perempuan juga bertentangan dengan prinsip-prinsip perlindungan anak dan hak anak. Hal ini dikarenakan praktik sunat perempuan dapat berpotensi terjadinya kekerasan dan eksploitasi anak karena kuasa orang tua atas tubuh anak seolah-olah tanpa batas. Dalam kasuskasus kekerasan dan eksploitasi anak dalam keluaraga, misalnya, kebanyakan kasus-kasus yang terjadi dilatarbelakangi oleh pandangan bahwa kewenangan orang tua terhadap anak seolah-olah tanpa batas.

Atas dasar kewenangan ini, maka orang tua bisa berdalih memiliki hak dan otoritas untuk menentukan. Sementara anak perempuan tersebut tidak memiliki kuasa atas tubuhnya sendiri hingga tubuhnya pun telah didefinisikan dan dikontrol melalui seperangkat tradisi yang disebut sunat perempuan.

Bahkan, dalam konteks tujuan sunat perempuan sebagaimana dijelaskan sebelumnya bahwa sunat perempuan bertujuan untuk mengendalikan nafsu syahwat perempuan agar tidak nginthil kakung atau hyperseks, maka kehidupan seksualitas anak perempuan telah diatur dan dirumuskan oleh banyak kepentingan di luar dirinya sendiri. Keluarga dan masyarakat demikian dominan didalam mengontrol tubuh perempuan itu. Kontrol atas tubuh anak perempuan, cenderung membuat anak-anak sangat rentan pada berbagai bentuk kekerasan dan eksploitasi dalam rumah tangga.

Dalam perspektif perlindungan anak, tradisi sunat perempuan yang dilakukan dengan cara melukai bagian dari alat kelamin perempuan sekecil apapun adalah kekerasan terhadap perempuan. Selain itu, juga merupakan tindakan yang merendahkan perempuan dan diskriminatif.

Jika dilihat dari tujuan sunat perempuan yang dimaksudkan untuk mengendalikan nafsu syahwat seorang perempuan agar tidak nginthil kakung atau hyperseks dengan cara disunat, maka hal itu justru bagian dari kekerasan terhadap anak perempuan. Pada konteks ini, sunat perempuan justru dapat berdampak buruk bagi perempuan. Dalam jangka panjang perempuan akan cenderung tidak bisa menikmati hubungan seksual dalam pernikahannya.

Dari perspektif feminisme, khitan perempuan menjadi bukti kuat bahwa perempuan tidak otonom atas tubuhnya sendiri. Tubuh perempuan menjadi medan pertempuran berbagai kepentingan sosial, tradisi, budaya, modal, dan 
agama. Perempuan tak memiliki hak dan otoritas untuk menentukan kekuasaannya atas tubuhnya sendiri. Kehidupan seksualitas perempuan diatur dan dirumuskan oleh banyak kepentingan di luar kepentingan perempuan itu sendiri. Karenanya muncul gerakan "revolusi seksual" untuk menghancurkan tatanan lama dan konservatif masyarakat yang bias gender. Keluarga, masyarakat, dan negara demikian dominan untuk mendefiniskan "apa tubuh perempuan itu". Masyarakat tradisional dan modern masih meyakini bahwa perempuan (dan tubuhnya) adalah realitas yang "kotor" dan "berdosa".

Dari sudut pandang Hak Asasi Manusia dan Perlindungan Perempuan, sunat perempuan menjadi dipermasalahkan karena apapun bentuk dan motivasi dilakukannya sunat pada perempuan akan melanggar Hak Asasi Perempuan, khususnya terkait dengan hak seksual dan kesehatan reproduksi setiap perempuan. Pada saat yang sama, praktik sunat perempuan yang selama ini dialami terutama oleh bayi-bayi perempuan bisa dilihat sebagai praktik pelanggaran hak anak sebagaimana yang telah dirativikasi oleh Pemerintah Indonesia dan juga negara-negara Muslim anggota OKI.

Dari sisi perlindungan hak anak, praktik ini dianggap tidak adil karena dilakukan terhadap bayi-bayi perempuan yang belum bisa mengeluarkan pendapatnya sendiri tentang bagaimana mereka ingin tubuhnya diperlakukan. Sehingga yang ada kemudian, anak-anak 'dipaksa' menerima perlakuan praktik khitan itu atas nama agama dan budaya/tradisi.

Dalam diskursus perlindungan anak, tradisi sunat perempuan jelas tidak sesuai dengan prinsip-prinsip pemberian kebebasan kepada anak (child liberation), dimana hak anak diinterpretasikan sebagai bentuk pemberian kebebasan kepada anak sebagai individu yang independen..$^{12}$ Dengan dilakukannya sunat terhadap anak perempuan, jelas seorang anak tidak menjadi 'subject of rights'. Jika seorang anak suda tidak lagi memiliki a katas dirinya sendiri, maka potensi terjadinya kekerasan dan eksploitasi anak semakin besar. Pada konteks ini, maka tradisi sunat perempuan bertentangan dengan prinsip-prinsip perlindungan anak perempuan.

\footnotetext{
${ }^{12}$ Kirk, S., The Sexual Abuse of Adolescent Girls, Social Worker's Child Protection Practice. Vermont: Ashgate, 1999); Goldstein, J., Solnit, A.J., Goldstein, S., \& Frued, A., The best Interests of the Child: The Least Detrimental Alternative (New York: The Free Press, 1998).
} 
Oleh sebab itu negara-negara di dunia, termasuk negara-negara muslim anggota OKI telah berupaya untuk menghapuskan praktik-praktik yang menindas dan menghancurkan kemanusiaan perempuan ini. Pada pasal 12 CEDAW (konvensi penghapusan segala bentuk diskriminasi dan kekerasan terhadap perempuan), hal ini juga dianggap sebagai bentuk kekerasan terhadap perempuan.

\section{Kesimpulan}

Dari pemaparan tentang sunat perempuan di Kabupaten Demak dapat ditarik beberapa kesimpulan sebagai berikut:

Pertama, ada masyarakat di Kabupaten Demak sebagai Representasi Masyarakat Pesisiran Jawa praktik sunat perempuan masih jamak ditemukan. Praktik sunat perempuan pada Kabupaten Demak dapat disimpulkan menjadi dua, yakni secara simbolik dan secara sesungguhnya. Yang dimaksud secara simbolik adalah praktik sunat perempuan dilakukan tidak dengan memotong sebagain anggota kelamin perempuan, yakni klitoris, melainkan menggunakan media pengganti, yakni kunyit, dan pada praktiknya kunyit tersebut yang dipotong. Sedangkan yang dimaksud secara sesungguhnya adalah bahwa sunat perempuan benar-benar dilakukan dengan cara memotong sebagian dari ujung klitoris anak perempuan, meskipun sedikit. Pada masyarakat Kabupaten Demak praktik sunat perempuan dilakukan ada yang secara simbolik dan ada yang sesungguhnya.

Kedua, waktu pelaksanaan sunat perempuan di masyarakat Kabupaten Demak pada umumnya bersamaan dengan upacara-upacara adat Jawa untuk bayi/anak kecil, yakni i). bersamaan dengan puputan (terputusnya tali pusar, umumnya usia bayi 7 hari), ii) wetonan bayi (usia bayi pas 35 hari/selapan ndino), iii) tidhak siti (upacara diperbolehkannya seorang anak menginjak tanah untuk pertama kalinya, biasanya usia bayi 7 bulan).

Ketiga, tujuan dilakukan sunat perempuan bagi masyarakat di Kabupaten Demak adalah agar anak perempuan tersebut menjadi anak shalihah dan seseorang yang nafsu syahwatnya bisa terkendalikan agar tidak "ngintil kakung" (hyperseks).

Keempat, motivasi menjalankan tradisi sunat perempuan bagi masyarakat di Kabupaten Demak adalah menjalankan tradisi leluhur yang telah turun temurun 
dari orang tua sejak zaman dahulu, dan menjalankan perintah agama karena adanya perintah khitan.

Kelima, di Indonesia, tradisi sunat perempuan masih menjadi kontroversi, ada yang mendukung dan ada juga yang menolak. Majelis Ulama Indonesia (MUI) mengeluarkan fatwa haram melarang praktik sunat perempuan, dan menghukumi praktik sunat perempuan sebagai sesuatu yang mulia (makrumah). Sementara Pemerintah Indonesia pernah melegalkan sunat perempuan melalui Peraturan Menteri Kesehatan No. 1636 Tahun 2010 tentang Tata Cara Sunat Perempuan, Akan tetapi, kemudian pemerintah membatalkan Permen tersebut melalui Permenkes Nomor 6 Tahun 2014 dengan alasan praktik sunat perempuan tidak memiliki manfaat apa-apa bagi kesehatan, justru bisa mendatangkan bahaya.

Keenam, jika dilihat dari perspektif gender, maka tradisi sunat perempuan, baik yang dilakukan secara sesungguhnya maupun dilakukan secara simbolik, merupakan tradisi yang bias gender, karena ia tidak dilepaskan dari makna kultural yang mempengaruhinya, yakni stigma tentang perempuan dalam budaya patriarki dimana perempuan harus disnat agar mengurangi syahwatnya. Artinya, tubuh perempuan dikontrol bukan oleh dirinya sendiri, melainkan oleh orang lain, terutama ole konstruksi maskulinitas. Sunat perempuan menjadi bukti bahwa perempuan tidak otonom atas tubuhnya sendiri. Tubuh perempuan menjadi medan pertempuran berbagai kepentingan sosial, tradisi, budaya, modal, dan agama.

Ketujuh, praktik sunat perempuan yang banyak dilakukan di Kabupaten Demak, baik yang dilakukan secara sesunggunya maupun secara simbolik, jika dilihat dari perspektif perlindungan anak dan ak asasi anak merupakan praktik kekerasan terhadap perempuan, dan oleh karenanya bertentangan dengan perlindungan perempuan dan melanggar hak asasi anak, khususnya terkait dengan hak seksual dan kesehatan reproduksi setiap perempuan. Dari sisi perlindungan hak anak, praktik ini dianggap tidak adil karena dilakukan terhadap bayi-bayi perempuan yang belum bisa mengeluarkan pendapatnya sendiri tentang bagaimana mereka ingin tubuhnya diperlakukan. Sehingga yang ada kemudian, anak-anak 'dipaksa' menerima perlakuan praktik khitan itu atas nama agama dan budaya/tradisi. 
Adapun rekomendasi yang dapat dilakukan adalah kepada tokoh agama, seyogianya menyampaikan secara detail landasan normatif dan historis terkait tradisi sunat perempuan kepada masyarakat agar didapatkan pemahaman yang menyeluruh di tengah masyarakat. Langkah ini bisa dilakukan melalui beberapa forum, seperti halaqah ulama untuk mendapatkan dukungan sunat perempuan. Kepada Masyarakat, hendaknya masyarakat secara terbuka terhadap berbagai informasi baru yang terkait dengan aspek kesehatan dan perlindungan anak, serta kritis dalam melaksanakan tradisi sunat perempuan yang berlangsung di tengah masyarakat. Kepada Dukun Bayi, seyogianya meningkatkan profesionalitas sebagai mitra tenaga medis (bidan) di dalam merawat bayi, seperti memandikan bayi, memijat bayi (ndadah), dan mencukur rambut. Kepada Tenaga Medis, seyogianya melakukan KIE (komunikasi, informasi, dan edukasi) secara intensif dan massif, baik kepada dukun bayi maupun masyarakat untuk meninggalkan tradisi sunat perempuan. Kepada Pemerintah, dalam hal ini terhadap beberapa institusi pemerinta meliputi:

1. Kementerian Pemberdayaan Perempuan dan Anak (Kemen PPA), perlu melakukan fasilitasi program-program dalam upaya pencegahan praktik sunat perempuan.

2. Kementerian Kesehatan, perlu melakukan koordinasi untuk merumuskan regulasi atau kebijakan yang mendukung upaya percepatan penghapusan praktik sunat perempuan.

3. Kementerian Agama, melalui penyuluh agama, kotib, dan mubaligh seyogianya melakukan KIE (komunikasi, informasi, dan edukasi) secara intensif dan massif agar masyarakat meninggalkan tradisi sunat perempuan.

4. Pemerintah Daerah, seyogianya melakukan koordinasi antar SKPD untuk pencegahan praktik sunat perempuan sesuai tupoksinya.[]

\section{Daftar Pustaka}

Abdul Wahab Khallaf, Imu Ushul al-Figh, Beirut: Dar al-Ilm, 1997.

Badan Pusat Statistik Kabupaten Demak, Kabupaten Demak dalam Angka 2016, , 2016. 
Badan Pusat Statistik Kabupaten Klaten, 2016, Kabupaten Demak dalam Angka 2016.

Debu Batara Lubis, Female Genital Mutilation: Penghilangan Hak Perempuan atas Tubuhnya, dalam Perempuan dan Hukum: Menuju Hukum yang Berperspektif Kesetaraan dan Keadilan, diterbitkan Yayasan Obor Indonesia bekerjasama dengan The Convention Watch Universitas Indonesia dan New Zealand Agency for International Development (NZAID), Jakarta, 2016.

Giladi, A., "Concepts of Childhood and Attitudes towards Children in Medieval Islam: A Preliminary Study with Special Reference to Reaction to Infant and Child Mortality". Journal of the Economic and Social History of the Orient, 32 (2), 1989.

Goldstein, J., Solnit, A.J., Goldstein, S., \& Frued, A., The best interests of the child: The least detrimental alternative. New York: The Free Press, 1998.

Hashemi, K., "Religious Legal Traditions, Muslim States and the Convention on the Rights of the Child: An Essay on the Relevant UN Documentation". Human Rights Quarterly, 2007, 29(1).

Ibn Hajar, Talkhish al-Habir, juz IV , 1964.

Kirk, S., The Sexual Abuse of Adolescent Girls, Social Worker's Child Protection Practice. Vermont: Ashgate, 1999.

Mosaffa, N., Does the Covenant on the Rights of the Child in Islam Provide Adequate Protection for Children Affected by Armed Conflicts? Muslim World Journal of Human Rights, 2011, 8(1).

Munawwir, A.W., Kamus al-Munawwir, Yogyakarta: Pustaka Progresif, 1984.

Munir, L. Z., 2006, Sunat dan Pelanggaran Hak, dalam http://situs.kesrepro.info/ gendervaw/okt/2006/gendervaw01.htm).

Nantabah, Zainul Khaqiqi, dkk., "Determinan Orang Tua dalam Perilaku Sunat Anak Perempuan di Indonesia" Buletin Penelitian Sistem Kesehatan, Vol. 18 No. 1 Januari 2015: 77-86.

al-Nawawi, Yahya ibn Syaraf, al-Majmu', Beirut: Dar al-Fikr, Cet. I, Juz II, 1996.

Ni'am, Asrorun, 2012, "Fatwa MUI tentang Khitan Perempuan," Jumal Ahkam Vol. XII, No. 2, Juli 2012.

Nurtawab, E., "Lebih Jauh dengan Khitan Perempuan," dalam http://www.icrp-online.org/wmprint.php? ArtID=345 
Rajabi-Ardeshiri, M., "The Rights of the Child in the Islamic Context: The Challenges of the Local and the Global", The International Joumal of Children's Rights, 17, 2009.

Ristiani, M., Ruli, N., dan Dian, P., Khitan Perempuan: Antara Tradisi dan Ajaran Agama, Yogyakarta: UGM dan Ford Foundation, 2003.

Rokhmah, I., Hani, U., "Sunat Perempuan dalam Perspektif Budaya, Agama dan Kesehatan: Studi Kasus di Masyarakat Desa Baddui Kecamatan Galesong Kabupaten Takalar Sulawesi Selatan", Jurnal Kebidanan dan Keperawatan, Vol. 11, No. 2, Desember 2015.

Shiab, Alwi., Islam Inklusif, Bandung: Mizan, 2001.

Syaltut, M., al-Fatawa, ttp: Dar al-Qalam, 1996.

Syed, S., "The Impact of Islamic Law on the Implementation of the Convention on the Rights of the Child: The Plight of Non-marital Children under Shari'a", The International Joumal of Children's Rights, 6(4), 1998.

Waliko, 2009, "Telaah atas Konsep Khitan bagi Wanita", Jumal Yinyang, Vol. 4 No. 2, Juli-Desember 2009. 